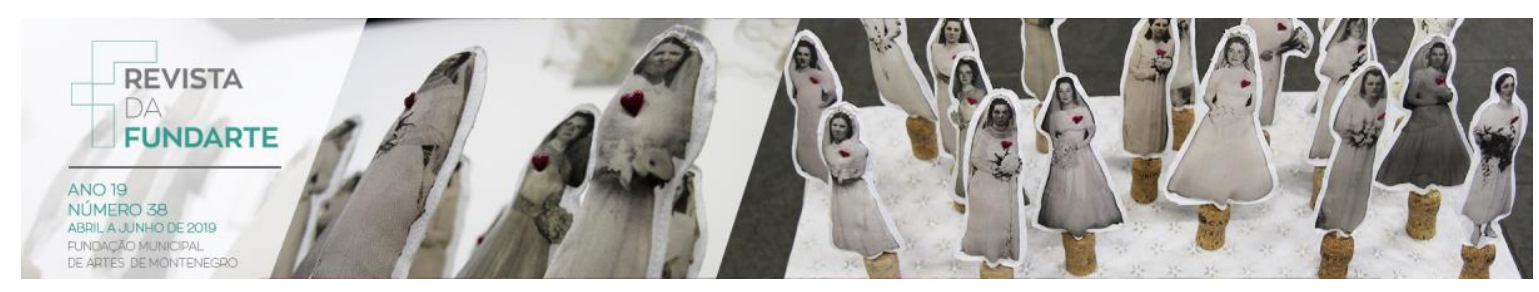

\title{
VÍNCULOS ENTRE O ENSINO DE ARTE E A LINGUAGEM AUDIOVISUAL NA CULTURA DIGITAL
}

\author{
Jéssica Thaís Demarchi ${ }^{1}$ \\ Cláudio Tarouco de Azevedo²
}

\begin{abstract}
Resumo: As ideias expostas no presente texto evidenciam a cultura digital e seu impacto causado através da linguagem audiovisual na sociedade contemporânea. Por intermédio de algumas reflexões levantadas nesse sentido, pretende-se estabelecer conexões entre o fluxo videográfico na contemporaneidade e 0 ensino de Arte. $O$ objetivo a partir daí consiste em estimular 0 desenvolvimento de ações pedagógicas, contextualizadas no âmbito da Arte, que explorem a prática audiovisual. Para tanto, ao final do artigo será descrita, ainda que brevemente, uma possibilidade de explorar o vídeo experimental através de oficinas.
\end{abstract}

Palavras-chave: Audiovisual; Ensino de Arte; Cultura digital.

\section{LINKS BETWEEN ART TEACHING AND THE AUDIOVISUAL LANGUAGE IN THE DIGITAL CULTURE}

\begin{abstract}
The ideas presented in this text highlight the digital culture and its impact through audiovisual language in contemporary society. Through some reflections raised in this direction, it is intended to establish connections between the videographic area in contemporaneity and the Art teaching. From that point, the objective is to stimulate the development of pedagogical actions contextualized in the scope of Art that explore audiovisual practice. Therefore, at the end of the text, a possibility to explore the experimental video through workshops will be briefly described.
\end{abstract}

Keywords: Audiovisual; Art teaching; Digital culture.

\begin{abstract}
1 Mestre (2018) em Artes Visuais pelo Programa de Pós-Graduação em Artes Visuais da Universidade Federal de Pelotas - PPGAV/UFPEL (linha de pesquisa: Ensino da Arte e Educação Estética). Durante o mestrado foi bolsista CAPES e participou do Núcleo Transdisciplinar de Estudos Estéticos/NUTREE liderado pela $\mathrm{Dr}^{\mathrm{a}}$ - Mirela Ribeiro Meira. Integrou o grupo de pesquisa \&quot;A produção de subjetividade em Félix Guattari: experiências com arte, ecologia e saúde\&quot; coordenado pelo Dr. Cláudio Tarouco de Azevedo. Graduou-se no curso de Licenciatura em Artes Visuais pela Universidade Federal do Rio Grande - FURG. Durante a graduação foi bolsista do Programa Institucional de Bolsa de Iniciação a Docência - PIBID/CAPES, e posteriormente monitora da disciplina de Processos de Criação e Análise de Imagem, ministrada pelo Dr. Marcelo Roberto Gobatto. Atuou como editora audiovisual nas emissoras rio grandinas FURG TV e FM e TV Mar. O foco de seu estudo abrange a Arte Contemporânea, a linguagem audiovisual na cultura digital, o ensino da Arte e a produção das subjetividades através do cinema. Durante o período de 04/2018 até 01/2019 atuou como professora substituta do núcleo de Design no Instituto Federal Sul-rio-grandense (câmpus Pelotas), nos cursos técnicos em Comunicação Visual e Design de Interiores, bem como no bacharelado em Design. Algumas das disciplinas que ministrou foram Fotografia, Teoria da Comunicação e Percepção.

2 Professor dos Cursos de Artes Visuais da Universidade Federal do Rio Grande - FURG e do Programa de Pós-Graduação (mestrado) em Artes Visuais da Universidade Federal de Pelotas UFPel. Coordena o Grupo de Pesquisa Arte, Ecologia e Saúde - GPAES. Pós-doutor em Artes Visuais (2016), doutor (2013) e mestre (2010) em Educação Ambiental e graduado em Artes Visuais Licenciatura (2006). Tem experiência nas áreas de Artes e Educação, atuando principalmente nos seguintes temas: arte e ecologia, arte e saúde mental, ecosofia, fotografia, audiovisual, arte educação ambiental, direito animal e biorrizoma.
\end{abstract}

DEMARCHI, Jéssica Thaís; AZEVEDO, Cláudio Tarouco de. Vínculos entre o ensino de Arte e a linguagem audiovisual na cultura digital. Revista da FUNDARTE, Montenegro, p.63-78, ano 19, oㅡ 38, abril/junho de 2019.

Disponível em: http://.seer.fundarte.rs.gov.br/index.php/RevistadaFundarte/index> 28 de junho de 2019. 


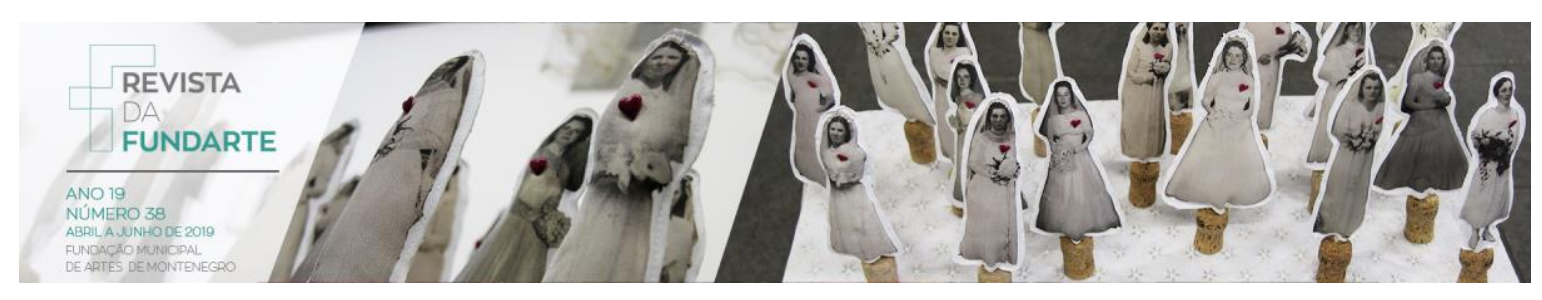

\section{Contextualizando a cultura digital}

A cultura digital manifesta profunda transformação na sociedade contemporânea. Também chamada de cibercultura, pode ser definida pelo autor André Lemos (2009, p. 135), quando diz que mesmo sendo a tecnologia algo fundamental no funcionamento da sociedade, é preciso ter cuidado ao nomear a cultura de acordo com os dispositivos tecnológicos. Ele explica que é necessário considerar que somos seres da política ou da comunicação e que precisamos reagir contra as dificuldades de expressão. Somos pessoas que precisam de artefatos para que seja possível ter controle em relação ao mundo externo, ao contrário de outros animais que vivem sem alterações muito refinadas no ambiente natural.

A nossa existência depende das transformações que operamos na natureza. Sendo assim, definir o nosso papel na sociedade significa compreender que somos seres políticos e da comunicação capazes de transformar o mundo por meio das tecnologias. Partindo de tal ponto de vista, Lemos diz que a "cibercultura seria a cultura contemporânea, onde os diversos dispositivos eletrônicos digitais já fazem parte da nossa realidade" (2009, p. 136).

Nesse sentido, as tecnologias que figuram a cultura digital não referem-se simplesmente aos processos de metamorfose energética e material do meio no qual vivemos. Para além disso, a sofisticação tecnológica viabiliza, de maneira mais fluente a cada dia que passa, transformações efetivas no campo da cultura, da política, da comunicação, e no âmbito social de maneira ampla. Em decorrência desse fenômeno, somos capazes de fazer com que a informação e multíplices tipos de significações sejam disseminados através de um "tráfego" tão ágil e célebre, como nunca havíamos presenciado em qualquer outra fase de nossa história.

Lemos (2013, p. 100) cita Breton para definir uma cronologia básica das primeiras etapas no tratamento automático da informação, dizendo que entre 1940 e 1960, as inovações e preceitos essenciais são delineados pela cibernética. Já a segunda fase, da década de 1960 até 1970, é representada por sistemas

DEMARCHI, Jéssica Thaís; AZEVEDO, Cláudio Tarouco de. Vínculos entre o ensino de Arte e a linguagem audiovisual na cultura digital. Revista da FUNDARTE, Montenegro, p.63-78, ano 19, no 38 , abril/junho de 2019.

Disponível em: http://.seer.fundarte.rs.gov.br/index.php/RevistadaFundarte/index> 28 de junho de 2019. 


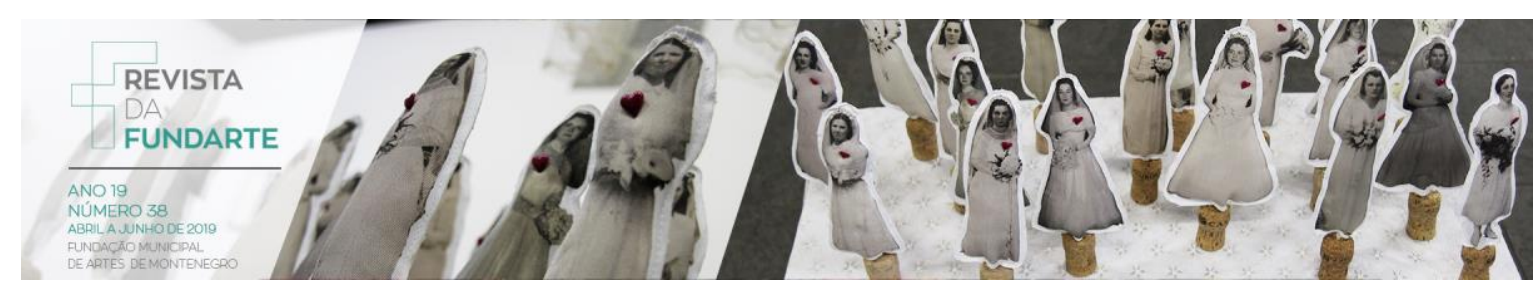

centralizados ligados à pesquisa militar e às universidades. O período entre 1970 até os dias atuais seria caracterizado pelos microcomputadores e redes telemáticas.

Para distinguir a sociedade informatizada da década de 1970 da sociedade do século $\mathrm{XXI}$, Lemos sugere uma quarta fase posicionada na metade da década de 1980 pontuada pela popularização do ciberespaço e sua integração na cultura contemporânea. Assim, tendo sido a terceira fase caracterizada pelo computador pessoal, a década de 1990, bem como o século XXI, indicam a era do computador conectado. Para melhor compreender a situação na qual ocorriam estas transformações que afetaram intensamente a cultura, Lemos define o surgimento da cibercultura:

Vamos situar o nascimento da cibercultura no surgimento da microinformática na metade dos anos 1970. A cibercultura, embora a expressão deva muito à cibernética, não é, no sentido exato, correlata a esta ciência. Antes, a cibercultura surge com os impactos socioculturais da microinformática. Mais do que uma questão tecnológica, o que vai marcar a cibercultura não é somente o potencial das novas tecnologias, mas uma atitude que, no meio dos anos 1970, influenciada pela contracultura americana, acena contra o poder tecnocrático. (LEMOS, 2013, p. 99).

Logo após o computador e a internet, surgem vários outros dispositivos tecnológicos: smartphones, tablets, aparelhos GPS que adquirem cada vez mais funções, videogames e jogos eletrônicos dinâmicos com novas possibilidades imersivas e aparelhos portáteis para escutar música. A sociedade passa a estar em rede, vivenciando uma espécie de cultura descentralizada e realidade virtual.

Esse conjunto de mudanças no campo tecnológico também atribui novas preocupações para os educarores, considerando que os indivíduos passam a ter acesso a uma participação intensa na cultura midiática. Levando em consideração que espectadores são também consumidores, é de grande relevância que as tramas tecidas pelo uso de tais tecnologias na cultura digital sejam esmiuçadas nos processos pedagógicos. Neste trabalho, discutiremos um recorte mais específico desse cenário: o audiovisual. Dessa forma, pretende-se instigar algumas conexões entre a linguagem do vídeo na contemporaneidade e o ensino de Arte.

DEMARCHI, Jéssica Thaís; AZEVEDO, Cláudio Tarouco de. Vínculos entre o ensino de Arte e a linguagem audiovisual na cultura digital. Revista da FUNDARTE, Montenegro, p.63-78, ano 19, ํㅡ 38, abril/junho de 2019.

Disponível em: http://.seer.fundarte.rs.gov.br/index.php/RevistadaFundarte/index> 28 de junho de 2019. 


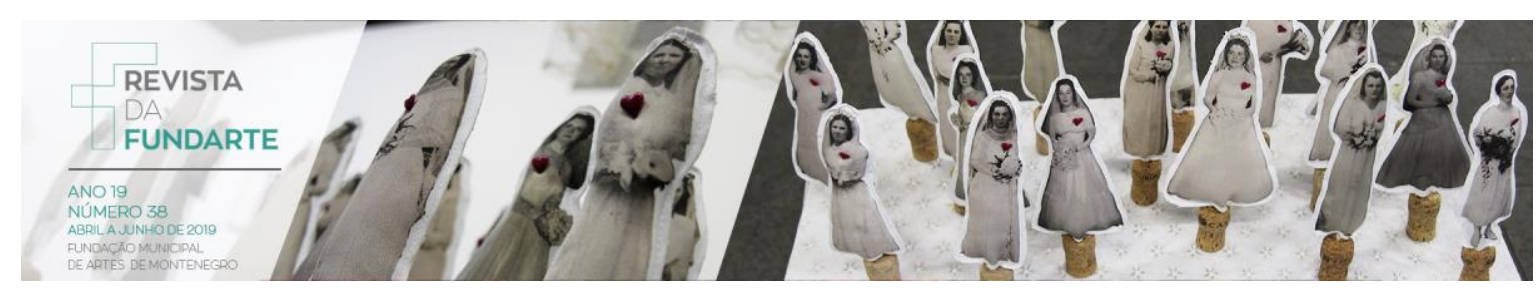

\section{Conectando a linguagem audiovisual e o ensino de Arte}

A relação entre 0 espectro das linguagens visuais e 0 ensino de Arte pode parecer um tanto quanto óbvia. Para levarmos adiante a reflexão proposta no presente trabalho, é imprescindível que saiamos do lugar comum dessa obviedade e pensemos em uma dilatação dos limites dessa relação contextualizada no âmbito do tratamento da Arte em processos pedagógicos.

Assim, pretende-se contribuir com micro intervenções que promovam a cultura das imagens ${ }^{3}$ e midiática no contexto pedagógico da Arte, mas com um enfoque mais específico no campo audiovisual.

Cláudia Zamboni de Almeida (2006) explica que a valorização da imagem é consenso pela grande maioria dos profissionais da educação comprometidos com a exploração das habilidades estéticas e artísticas. Dessa forma, é extremamente importante que esses educadores se perguntem se os conteúdos selecionados a serem trabalhados em Arte "estão dando conta das imagens divulgadas na televisão, publicidade, e outros meios que usam a imagem para comunicar" .(ALMEIDA, 2006, p. 73).

Segundo a autora, as relações entre humano e tecnologia podem muitas vezes passar despercebidas pelo homem e nesse sentido, a arte desempenha um papel fundamental: o de desvelar essas relações, conectando o homem e as tecnologias em enlaçamentos sensíveis. O convívio com uma vasta rede de mídias torna ainda mais evidente a afirmação da importância da consideração desse contexto pelo ensino de Arte. Isto posto, Almeida (2006, p. 82) constata que:

Nas últimas décadas, o avanço tecnológico provoca os sentidos e desafia o homem contemporâneo, que se vê aturdido e seduzido com o que é possível e permitido pelo desenvolvimento científico. Este homem navega em espaços virtuais simultâneos, não lineares. Informações flutuam e recriam-se no imaginário. Situações interativas que o video game, a Internet, o CD-ROM exploram e que a arte contemporânea traz para o

\footnotetext{
3 Os autores Raimundo Martins e Pablo Sérvio (2012) caracterizam a cultura das imagens ou midiática através dos repertórios midiáticos (estes repertórios envolvem imagem e sonoridades, além da palavra escrita e oralizada) difundidos pelos meios de comunicação midiáticos, que por sua vez, operam como agentes sociais e educativos que disseminam padrões, comportamentos e valores.
}

DEMARCHI, Jéssica Thaís; AZEVEDO, Cláudio Tarouco de. Vínculos entre o ensino de Arte e a linguagem audiovisual na cultura digital. Revista da FUNDARTE, Montenegro, p.63-78, ano 19, oㅡ 38, abril/junho de 2019.

Disponível em: http://.seer.fundarte.rs.gov.br/index.php/RevistadaFundarte/index> 28 de junho de 2019. 


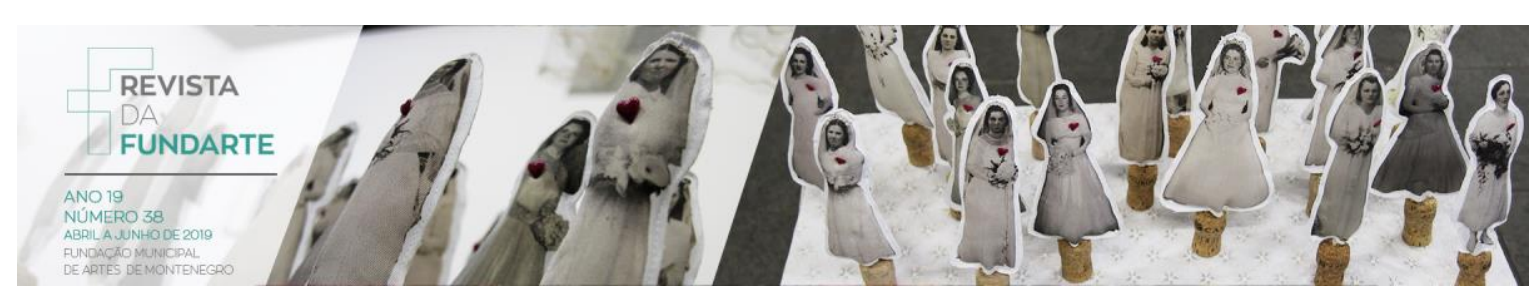

mundo sensível, exigem capacidades perceptivas e intelectuais diferenciadas das de outros tempos.

Ao prosseguir no rumo desta linha de pensamento, Almeida nos alerta sobre a relevância de estruturar as ações desenvolvidas no bojo do ensino de Arte, de maneira que estas contribuam com uma formação conectada ao tempo em que o sujeito constitui sua existência. E é nos cordões da malha da cibercultura que os indivíduos instituem-se, mais do que nunca, nos liames de uma trama que prolifera informações visuais, audiovisuais, sonoras e midiáticas em geral.

Esse cenário edifica-se sob as égides de velozes transformações tecnológicas que, ao estabelecer parcerias com as grandes corporações ao redor do mundo, contribuem com a velha fórmula da indústria cultural a fim de manter o fluxo do consumo tão intenso quanto for possível. Destarte, evidencia-se a relevância de repensar a Arte em suas extensões educacionais para que seja possível acompanhar as inovações tecnológicas da comunicação da atualidade. Ao mesmo tempo, pretende-se buscar a criação de mecanismos que constatem e problematizem os artifícios de um pretenso controle sobre a mentalidade da população através da imageria midiática.

\section{A televisão e a fluência do audiovisual na contemporaneidade}

A manifestação audiovisual constitui parte das inovações tecnológicas contemporâneas responsável pela ampliação das redes sociais. São diferentes as formas como ela marca essa experiência, de uma maneira ainda mais pluralizada através do acesso a diferentes categorias de conteúdos propiciadas pela internet. Assim, tentar restringir ou classificar o vídeo, cuja presença é inegável na atualidade, a uma ou mais esferas específicas da vida da população seria um esforço vão.

O campo do audiovisual contextualizado na fase contemporânea exerce um papel alargado e em numerosas instâncias da experiência anfêmera. Ele marca presença, só para citar alguns casos, no cinema, nos videogames, nos telões

DEMARCHI, Jéssica Thaís; AZEVEDO, Cláudio Tarouco de. Vínculos entre o ensino de Arte e a linguagem audiovisual na cultura digital. Revista da FUNDARTE, Montenegro, p.63-78, ano 19, ํㅡ 38, abril/junho de 2019.

Disponível em: http://.seer.fundarte.rs.gov.br/index.php/RevistadaFundarte/index> 28 de junho de 2019. 


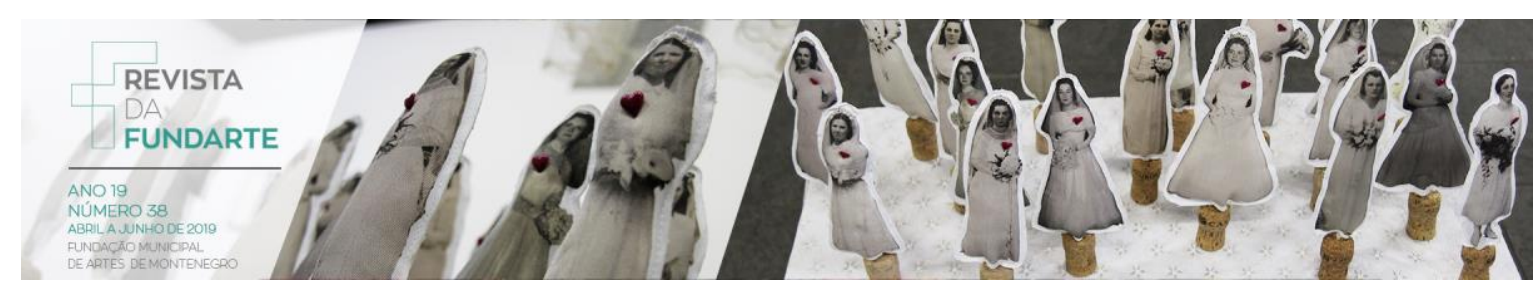

publicitários, na grade televisiva, nas inúmeras plataformas online de hospedagem de conteúdo audiovisual, nos aplicativos de dispositivos móveis de comunicação, na videoarte e em multiformes manifestações artísticas e culturais às quais o vídeo é de alguma forma agregado.

Segundo Marcia Nogueira Alves (2008), a importância do papel exercido pela comunicação audiovisual no organismo social em que vivemos atualmente alcança níveis supremos de atividade. Os indivíduos tornam-se seres audiovisuais de forma que as experiências que compõem o percurso de suas vidas são transpassadas pelos mais variados fenômenos mediados pela tecnologia audiovisual.

O vídeo nos acompanha em grande parte do cotidiano. Na maioria dos estabelecimentos que frequentamos existem um ou mais televisores exibindo diferentes tipos de programação televisiva, filmes ou mesmo um circuito de campanhas específicas que promovem o serviço prestado pelo estabelecimento. Nas redes sociais somos bombardeados por vídeos aleatórios, os quais muitas vezes assistimos sem nem ao menos ter tido a intenção, mas a reprodução automática dos mesmos acaba nos atraindo para sua mensagem. Em galerias de arte, cada vez mais podemos ver o trabalho de artistas que se propõem a desenvolver poéticas em vídeo. No celular que carregamos conosco, ao qual direcionamos grande parte de nossa atenção diária, recebemos e assistimos diversificados tipos de conteúdo audiovisual. E é também através deste dispositivo, cada vez mais sofisticado, que produzimos vídeos para compartilhar com tantas pessoas quanto desejarmos. Nesse sentido, Alves (2008, p. 19) comenta:

\footnotetext{
Vivemos numa época em que o audiovisual é o modo de expressão predominante. Na mídia, na arte, na ciência, na tecnologia, na forma como nos comunicamos, o audiovisual está presente em tudo. Novas mídias audiovisuais se multiplicam ao mesmo tempo em que mídias tradicionais são convertidas em formato digital. [...]Mediados pela cultura do audiovisual, cada vez mais interagimos e fazemos parte do mundo por meio dele.
}

Tendo em mente as multifacetadas funções do trânsito audiovisual na sociedade contemporânea, se faz interessante pensar no aparelho televisor, o precursor da disseminação massiva da linguagem audiovisual. Alves (2008, p. 65)

DEMARCHI, Jéssica Thaís; AZEVEDO, Cláudio Tarouco de. Vínculos entre o ensino de Arte e a linguagem audiovisual na cultura digital. Revista da FUNDARTE, Montenegro, p.63-78, ano 19, ํㅡ 38, abril/junho de 2019.

Disponível em: http://.seer.fundarte.rs.gov.br/index.php/RevistadaFundarte/index> 28 de junho de 2019. 


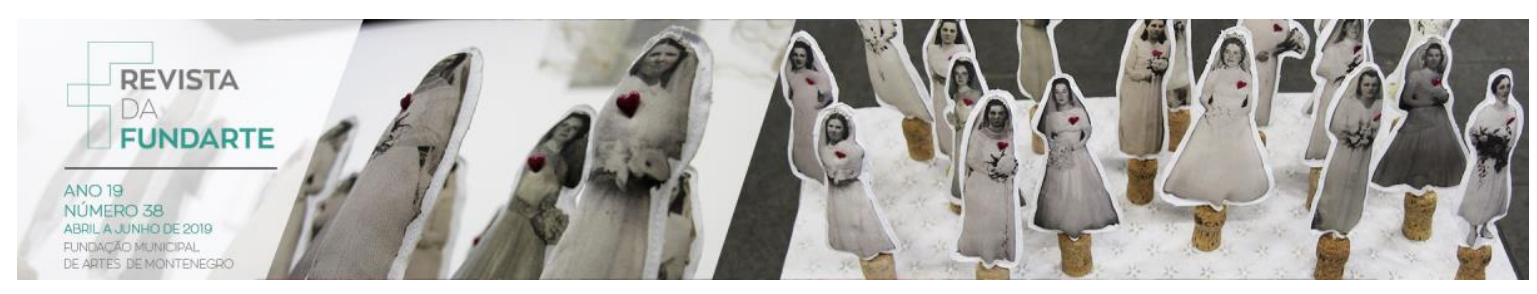

explica que no Brasil, ao contrário do rádio que foi introduzido através de uma proposta mais voltada à cultura, a televisão apresentou-se como um sistema primordialmente comercial. Após a sua inauguração na década de 1950, ela tornouse muito rapidamente o difusor de maior sucesso das campanhas publicitárias das principais multinacionais. A televisão precisou de apenas um ano de funcionamento no país para que seu montante de verba designado para a projeção dessas publicidades comerciais se tornasse muito superior ao do rádio.

A partir daí, o papel ocupado pela televisão em nosso cotidiano cresceu energicamente. Aos poucos, chegamos em um tempo presente no qual podemos assistir a todo tipo de conteúdo, seja ele de caráter fantástico, violento, divertido e por aí se segue em um catálogo infindável. Alves (2008, p. 60) diz que a verdade é que a televisão configura um extraordinário meio audiovisual que, através de sua incorporação assídua em nosso cotidiano, tornou-se capaz de influenciar intensamente nossas opiniões e modos de apreender a vida. Dessa forma, o aparato midiático atrai para si até os dias de hoje diversas críticas.

Atualmente é possível assistir a conteúdos audiovisuais em outros dispositivos, como o celular e o computador. O atual e veloz trânsito simultâneo e interativo das mídias que evidencia uma convergência tecnológica vem transformando as formas de criação, produção e disseminação das informações. Assim, a televisão, ao contrário de esgotar-se em si mesma, busca criar atrações e mecanismos inéditos, tanto para não perder aqueles que já são espectadores de sua programação, quanto para atrair um novo público.

Um caso que pode exemplificar essa dinâmica é o Globo Play, um aplicativo inaugurado pela Rede Globo no final de 2016. Na interface do mecanismo, além de serem oferecidos outros recursos, é possível acessar conteúdos da emissora com exclusividade. Dessa maneira, configura-se uma mescla entre a televisão e outros dispositivos nos quais o aplicativo pode ser acessado (celular smartphone e computador), podendo abranger assim um público mais diversificado, tendo em vista que atualmente muitas pessoas utilizam o celular, por exemplo, com uma frequência

DEMARCHI, Jéssica Thaís; AZEVEDO, Cláudio Tarouco de. Vínculos entre o ensino de Arte e a linguagem audiovisual na cultura digital. Revista da FUNDARTE, Montenegro, p.63-78, ano 19, ํㅡ 38, abril/junho de 2019.

Disponível em: http://.seer.fundarte.rs.gov.br/index.php/RevistadaFundarte/index> 28 de junho de 2019. 


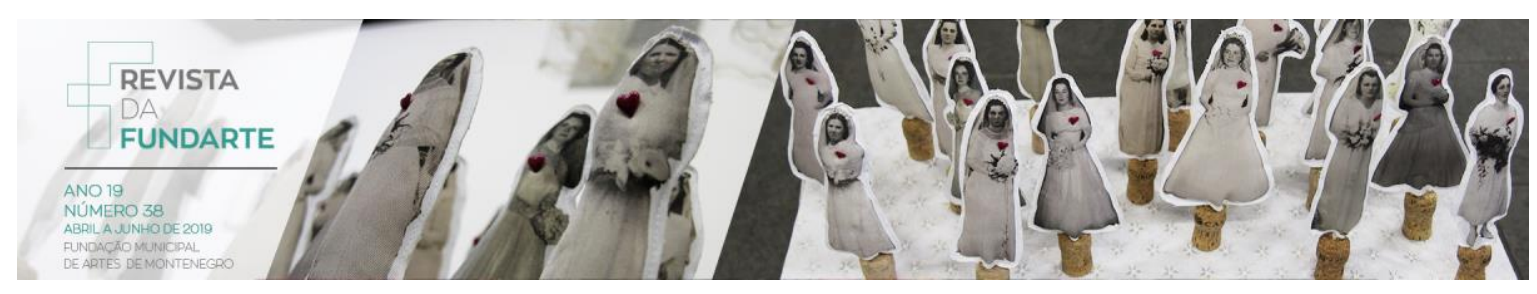

bastante superior em relação ao televisor. A autora Alves (2008, p. 125) sintetiza a convergência das mídias dizendo que:

Juntamente com as mídias, o telefone e o computador escrevem um novo capítulo da história da comunicação e dos homens, no qual as novas tecnologias são protagonistas, afetando diretamente nossas vidas e a forma como nos comunicamos. Nesse contexto, não seria descabido dizer que o audiovisual tornou-se uma linguagem universal. Afinal, a performance de todas essas novas mídias e tecnologias incorpora o audiovisual como base.

Entendendo a comunicação audiovisual como uma linguagem universal, portanto, extremamente participante da vida cotidiana, fica evidente mais uma vez, a importância de sua exploração nas tramas do ensino de Arte. Na próxima seção, discutiremos o vídeo por intermédio do viés experimental, para que na sequência possamos introduzir uma possibilidade de trabalhar com essa expressão em oficinas de vídeo experimental.

\section{Hibridismo e experimentação audiovisual}

O audiovisual, além de absorver a linguagem da televisão, herdou também certa tendência a movimentar-se como uma espécie de instrumento a serviço de outros encadeamentos de subjetivação. Não seria desmoderado presumir que mesmo depois de uma evolução alucinada em termos tecnológicos no meio audiovisual, sua linguagem ainda seja empregada inúmeras vezes de maneira reducionista, talvez como simples aparato a serviço do consumo, como acontece corriqueiramente na indústria cultural.

Referindo-nos, especialmente, ao viés experimental do vídeo, o espectro das formas videográficas é extremamente amplo e não precisa delimitar-se a sistematizações que classifiquem suas figurações como certas ou erradas, como acontece na gramática das línguas naturais, por exemplo. Nesse caso, a linguagem audiovisual é maleável e não depende de um conjunto de normas para que se faça entender, mesmo porque sua "mensagem" se vislumbra aberta a múltiplos impulsos de significação. O vídeo, em sua flexão de vetor artístico, não tem a necessidade de

DEMARCHI, Jéssica Thaís; AZEVEDO, Cláudio Tarouco de. Vínculos entre o ensino de Arte e a linguagem audiovisual na cultura digital. Revista da FUNDARTE, Montenegro, p.63-78, ano 19, ㄲo 38, abril/junho de 2019.

Disponível em: http://.seer.fundarte.rs.gov.br/index.php/RevistadaFundarte/index> 28 de junho de 2019. 


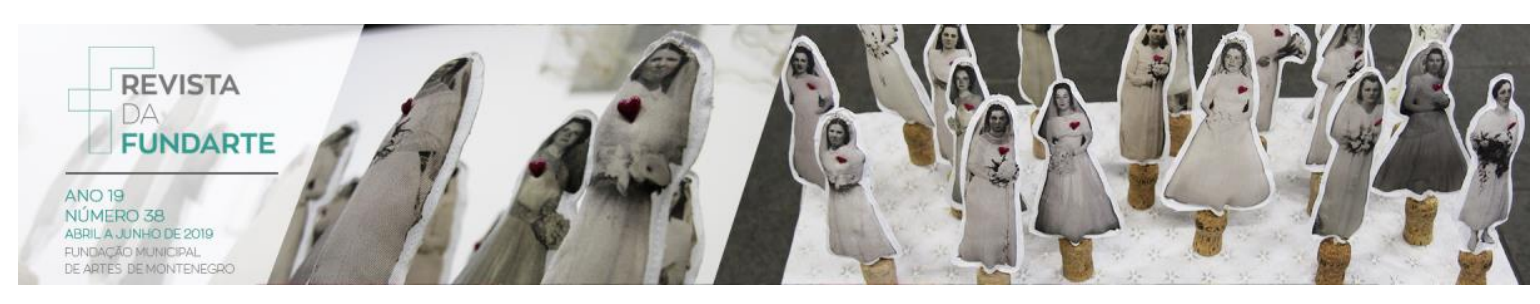

se fazer compreender de maneira unilateral, muito menos de ficar enclausurado no interior de um conjunto de regras que ditam a sua qualidade.

Estamos falando do alcance das possibilidades dessa expressão, o que não significa que não existam audiovisuais que optem por obedecer a uma série de regras e por limitar ao máximo a sua latência enquanto dispositivo de significação. Basta olhar para o audiovisual na publicidade, onde os comerciais utilizam e desenvolvem recursos para disseminar mensagens que não se distanciem da noção de que o produto ou ideia anunciada é conveniente e que seu consumo garante sucesso e maior qualidade de vida.

Portanto, nosso objetivo é trabalhar na perspectiva do vídeo experimental, do seu vasto e mutável leque de possibilidades de produção. Assim, entendamos esse tipo de vídeo no sentido de criações que não se curvam a padrões visuais ou de conteúdo, e que não necessitam firmar compromisso com o circuito comercial. Mais do que isso, a videografia experimental abrange as produções marcadas pelo protagonismo do ato de experimentar, de arriscar, testar materiais e operações diferentes a fim de desvelar novas possibilidades, novos sentidos e sensações.

Os autores Arlindo Machado (2011) e Christine Mello (2008) compartilham da visão de que o vídeo opera como um complexo híbrido entre outros códigos de expressão como o cinema, a música, o desenho e a computação gráfica. Nessa lógica, Mello (2008, p. 28-29) afirma que o movimento videográfico colhe estilhaços em multíplices manifestações da arte e "encontra formas muito mais complexas de extrapolar a sua própria pluralidade interna e produzir um alargamento de sentidos". Ou seja, a prática do vídeo se esgueira por entre outras expressões artísticas sendo capaz de dilatar seu alcance de significação, desembocando em poéticas singulares e inovadoras.

Segundo Machado (2011, p. 176), nos meandros da década de 1960, quando a linguagem audiovisual inaugura a sua prática como uma nova forma de manifestação artística, já estava em queda a ideia de uma linguagem pura ou específica na esfera videográfica.

DEMARCHI, Jéssica Thaís; AZEVEDO, Cláudio Tarouco de. Vínculos entre o ensino de Arte e a linguagem audiovisual na cultura digital. Revista da FUNDARTE, Montenegro, p.63-78, ano 19, ํㅡㅇ, abril/junho de 2019.

Disponível em: http://.seer.fundarte.rs.gov.br/index.php/RevistadaFundarte/index> 28 de junho de 2019. 


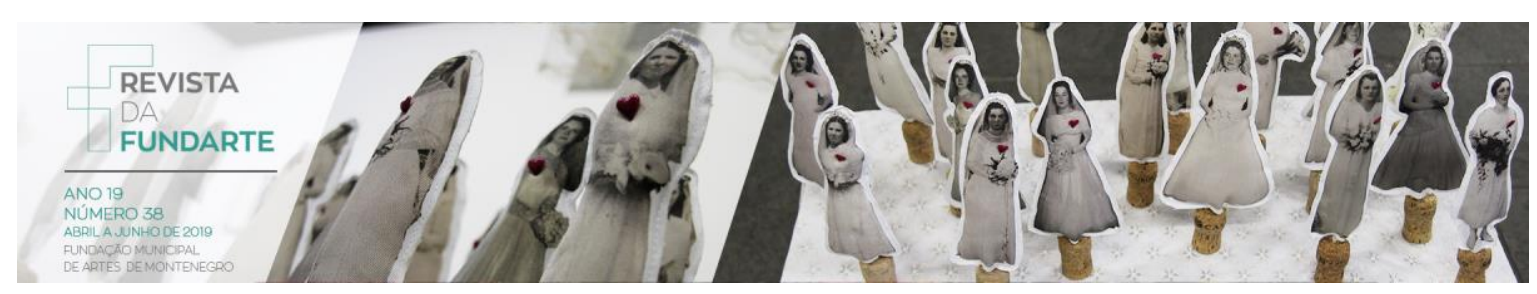

A videoarte já em seus primórdios encontrava válvulas de escape que se opunham às configurações televisivas, das quais havia herdado o idioma. $O$ audiovisual engendrava-se em um contexto artístico determinado a superar regras e tendências da linguagem convencional. Machado (2011, p. 183) afirma que:

Longe de se deixar escravizar por uma norma, por um modo padronizado de se comunicar, por uma "linguagem" no sentido restritivo do termo, cada obra, na verdade, reinventa a maneira de se apropriar de uma tecnologia enunciadora como o vídeo. Nesse sentido, as "possibilidades" dessa tecnologia estão em permanente mutação e crescem na mesma proporção de seu repertório de obras.

A constante presença do dinamismo audiovisual na paisagem de outras manifestações, faz com que seja comum ter a impressão de que "tudo é vídeo na contemporaneidade" (MELLO, 2008, p. 27), evidenciando assim a expansão de seu alcance e aplicações.

Apesar de seu trânsito ser mais frenético entre as vias eletrônicas/digitais, 0 vídeo consegue imbricar-se também por entre inúmeras outras manifestações no campo das ações políticas, ambientais e toda uma variedade de enunciados pertinentes ao desenvolvimento do organismo social. Isso ocorre tanto por intermédio dos métodos mais tradicionais quanto dos mais alternativos e avançados tecnologicamente, caracterizando assim uma descentralização das formas de expressão, já que as linguagens são mescladas através de diferentes processos e em ambientes distintos.

\section{Oficinas de vídeo experimental}

Tendo em mente as reflexões anteriormente colocadas no presente artigo, foi desenvolvido um programa de oficinas de vídeo experimental como protótipo de ação pedagógica a ser realizada no contexto do ensino de Arte. A proposta foi criada tendo em vista a possibilidade de ser aplicada em diferentes ciclos e ambientes de

DEMARCHI, Jéssica Thaís; AZEVEDO, Cláudio Tarouco de. Vínculos entre o ensino de Arte e a linguagem audiovisual na cultura digital. Revista da FUNDARTE, Montenegro, p.63-78, ano 19, ํㅡ 38, abril/junho de 2019.

Disponível em: http://.seer.fundarte.rs.gov.br/index.php/RevistadaFundarte/index> 28 de junho de 2019. 


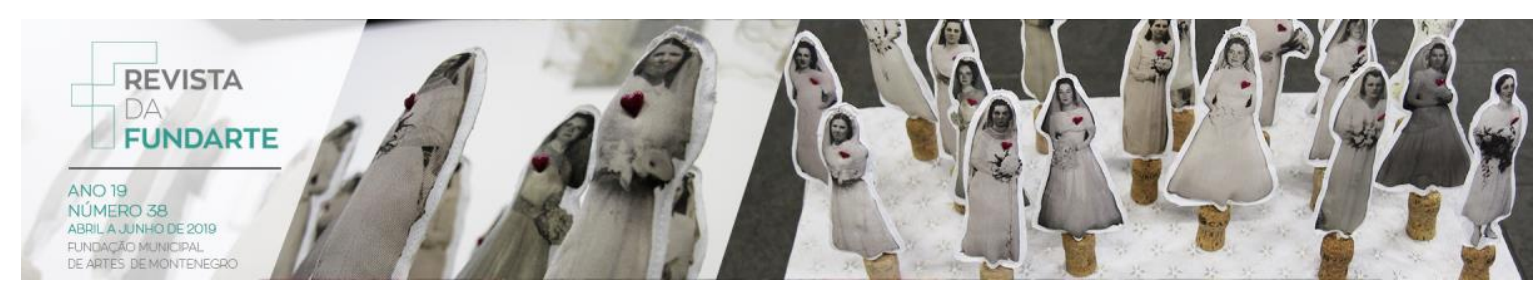

ensino, desde que realizadas algumas adaptações de acordo com faixa etária e necessidade dos participantes em questão.

O programa conta com sete oficinas ${ }^{4}$ e cada uma delas é dividida em quatro etapas principais. A primeira etapa consiste em explorar alguns fragmentos audiovisuais provenientes dos repertórios midiáticos consumidos diariamente, sobretudo os da televisão aberta brasileira. A partir daí, vislumbra-se uma análise desses materias no sentido de uma via dupla. Há uma tentativa de entender de que forma as mensagens propagadas por essa mídia retratam a realidade da sociedade em que estamos inseridos. Por outro lado, são propostos diálogos e experiências que visam perceber alguns mecanismos presentes nesses conteúdos para questionar a forma como eles possivelmente pretendem influenciar nosso comportamento e, consequentemente, surtir uma padronização das subjetividades. O princípio da exploração da mídia no decorrer das oficinas vai de encontro à visão de Martins e Sérvio a respeito da escola e dos processos educacionais:

[...] cremos que a escola deve engajar-se num projeto de inclusão que seja responsável contribuindo para uma crítica das imagens que nos circundam. Uma inclusão que considere pensar a multiplicidade de imagens, a complexidade dos interesses a partir dos quais são produzidas e a relação ambígua, de amor e resistência que podemos, como receptores, ter com elas. (MARTINS; SÉVIO, 2013, p. 274).

Nesse sentido, a análise dos materiais da mídia audiovisual que serão abordados na proposta das oficinas de vídeo experimental não pretende condenar a televisão. O que se deseja é constatar, através de um olhar questionador, alguns artifícios da mídia que podem contribuir com a uniformização das subjetividades, a fim de desnaturalizá-los e compreender como o sistema econômico capitalista os emprega a favor de sua manutenção. Para além disso, também pretende-se investigar algumas possibilidades presentes nessa mesma mídia, de enxergar o

\footnotetext{
${ }^{4}$ Cada uma das sete oficinas trata de um assunto diferente, sendo alguns deles: Representatividade na mídia; Consumismo e geração de lixo no sistema capitalista; Formas de preconceito; Padronização das subjetividades através da grande mídia televisiva; Empatia. Para conferir o detalhamento de cada oficina, basta consultar a dissertação intitulada "Videografias experimentais no ensino de Arte: frames da produção de subjetividades"1 (DEMARCHI, 2018).

'Disponível em: http://guaiaca.ufpel.edu.br:8080/handle/prefix/4421?mode=full
}

DEMARCHI, Jéssica Thaís; AZEVEDO, Cláudio Tarouco de. Vínculos entre o ensino de Arte e a linguagem audiovisual na cultura digital. Revista da FUNDARTE, Montenegro, p.63-78, ano 19, ํㅡㅇ, abril/junho de 2019.

Disponível em: http://.seer.fundarte.rs.gov.br/index.php/RevistadaFundarte/index> 28 de junho de 2019. 


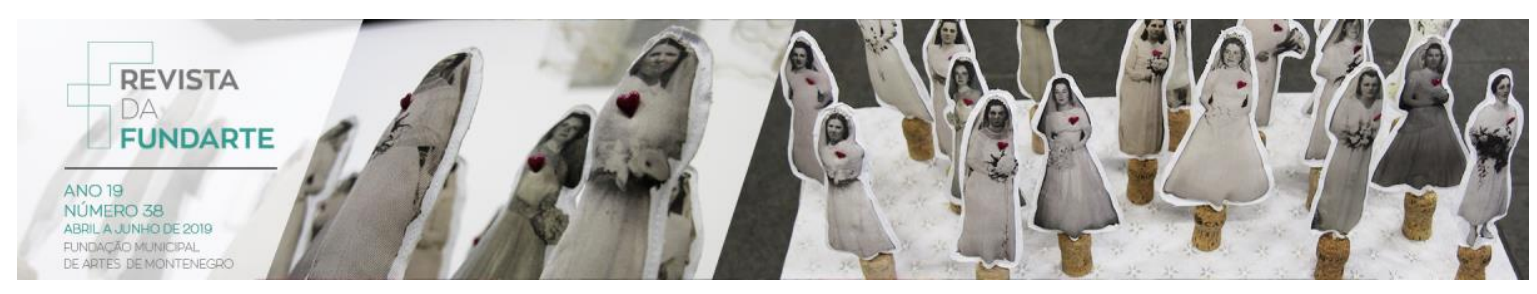

diferente e de propiciar diálogos que se coloquem na contramão das padronizações e demais formas de preconceito e exclusão. Por intermédio dessa dualidade, a mídia audiovisual é evocada como um disparador de problematizações que visam produzir dispositivos de luta contra as opressões que compõem o bojo das desigualdades.

Além de analisar os materiais audiovisuais provenientes dos veículos midiáticos e os vídeos produzidos pelos próprios participantes das oficinas, é interessante que também se trabalhe com videoartes experimentais. Destarte, será viável enriquecer o repertório dos integrantes da proposta, de modo que estes possam conhecer possibilidades da prática videográfica que diferem dos padrões imagéticos audiovisuais que consumimos incessantemente no dia a dia.

Depois de assistir e debater os materiais selecionados, na segunda etapa são propostas algumas dinâmicas práticas como uma espécie de laboratório de experimentação dos pensamentos e ideias levantadas durante a discussão que as antecedem. Essas atividades pretendem também entrosar os discentes e educador (es) para que seja possível relacionar os debates em pauta com as situações do cotidiano de cada participante das oficinas, tornando esse diálogo mais convidativo.

Por sua vez, estas experiências alimentam a terceira fase das oficinas, que é a produção dos vídeos experimentais. O material audiovisual produzido pelos participantes das oficinas é uma tentativa de expressar de maneira artística e experimental as significações engendradas durante a análise dos conteúdos midiáticos, bem como nas dinâmicas realizadas posteriormente, conectando essas ideias com suas vivências cotidianas. É importante que os alunos tenham bastante liberdade no processo para experimentar diferentes técnicas de composição visual, sonora e narrativa, de captação de imagem e de edição. São trabalhos que nascem do desejo de desvelar subjetividades que se esquivam de padrões prefixados através do ato de experimentar o novo e o desconhecido.

Já a quarta etapa das oficinas propõe uma exibição dos trabalhos realizados pelos discentes, seguida de uma troca de ideias sobre os vídeos apresentados. Nesse momento não só os realizadores dos trabalhos podem falar sobre os conceitos e etapas de seus processos de criação, mas também os colegas devem

DEMARCHI, Jéssica Thaís; AZEVEDO, Cláudio Tarouco de. Vínculos entre o ensino de Arte e a linguagem audiovisual na cultura digital. Revista da FUNDARTE, Montenegro, p.63-78, ano 19, ํㅡ 38, abril/junho de 2019.

Disponível em: http://.seer.fundarte.rs.gov.br/index.php/RevistadaFundarte/index> 28 de junho de 2019. 


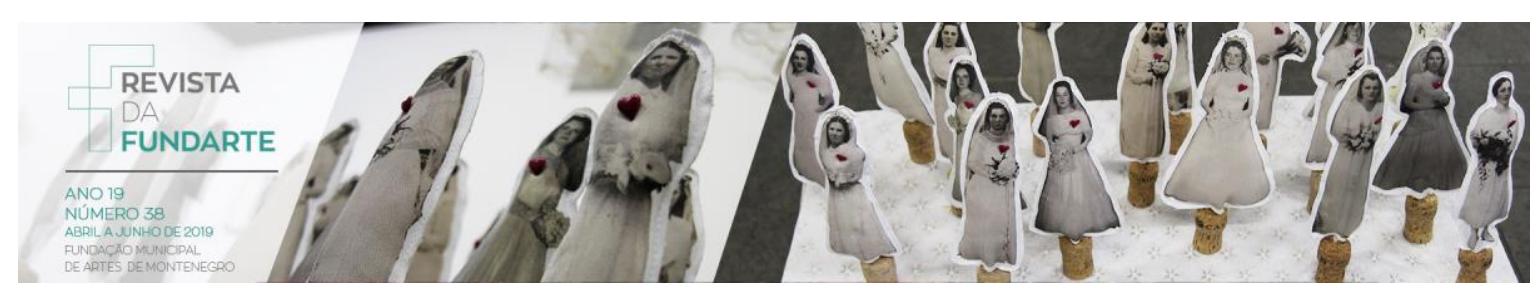

dar sua opinião sobre aquilo que assistiram. Dessa forma, os autores podem conhecer novas possíveis interpretações e potências de seus trabalhos, já que o olhar do outro é capaz de revelar ideias até então não pensadas pelo idealizador do vídeo.

Para melhor exemplificar o funcionamento das oficinas integrantes do programa em questão, abaixo encontra-se a descrição de uma delas, denominada como "oficina do elemento secreto":

Nessa ação, um mesmo acontecimento é analisado pela turma participante através de fragmentos audiovisuais de dois ou três diferentes veículos midiáticos, podendo ser de canais televisivos em comparação com alguma plataforma de disseminação de informação online, por exemplo. Depois de assistir esses materiais e discutir as variadas maneiras que um mesmo fato pode ser retratado, de acordo com a intenção do veículo que propaga aquele conteúdo, é proposta uma experiência.

O (a) educador(a) que ministra a oficina, apresenta dois recipientes para a turma, cujo conteúdo não pode ser visto de fora e os participantes devem tentar adivinhar, de acordo com as pistas dadas pelo (a) professor (a), qual é o conteúdo de cada recipiente. A respeito do primeiro receptáculo, o (a) educador (a) atribui algumas características pejorativas, já em relação ao segundo, são conferidos elogios que o prestigiem. As tentivas de adivinhar o conteúdo de cada recipiente devem ser anotadas, e caso alguém arriscar dizer que ambos possuem o mesmo objeto em seu interior, o (a) ministrante da oficina deve negar.

Depois de já terem sido dados vários palpites acerca do que poderia estar dentro de cada recipiente, o (a) professor (a) mostra para a turma os elementos secretos que estavam no interior de cada um: eis que ambos os invólucros guardavam objetos iguais. A dinâmica pretende reforçar a ideia de que uma mesma ideia ou produto pode ser "vendido" de diferentes maneiras, indo ao encontro da análise dos fragmentos audiovisuais midiáticos feita anteriormente. Faz-se também uma alusão ao fato de que muitas vezes a mídia distorce a situação dos acontecimentos, como acontece na dinâmica do elemento secreto, no caso da

DEMARCHI, Jéssica Thaís; AZEVEDO, Cláudio Tarouco de. Vínculos entre o ensino de Arte e a linguagem audiovisual na cultura digital. Revista da FUNDARTE, Montenegro, p.63-78, ano 19, ํㅡ 38, abril/junho de 2019.

Disponível em: http://.seer.fundarte.rs.gov.br/index.php/RevistadaFundarte/index> 28 de junho de 2019. 


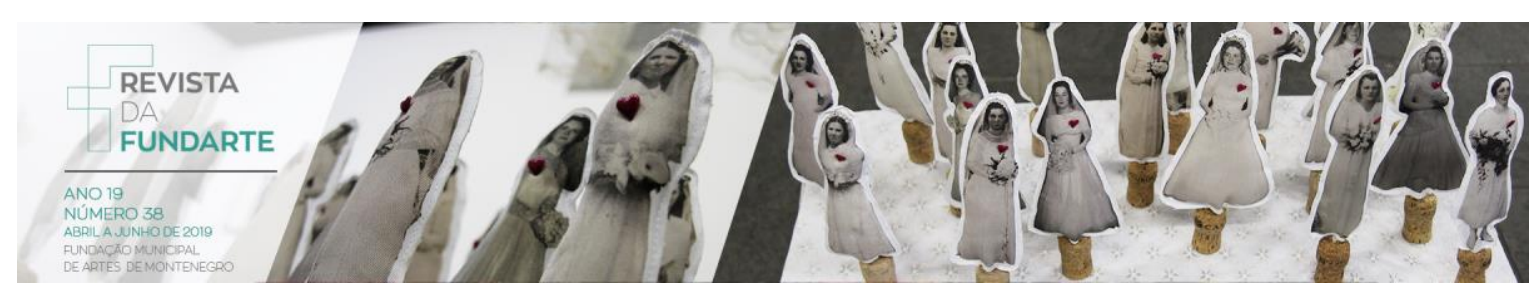

resposta negativa em relação ao palpite de que ambos recipientes possuíam o mesmo conteúdo.

O próximo passo consiste na produção dos vídeos experimentais, que devem buscar manifestar audiovisualmente as reflexões discutidas no decorrer das experiências. Depois que os vídeos estiverem prontos, é importante que haja um momento para que os partipantes da oficina possam assistir os vídeos uns dos outros. Nesse momento, há um diálogo sobre o processo de criação de cada um e sobre como as discussões engendradas durante a oficina resultaram em diferentes poéticas artísticas através da prática videográfica.

\section{Breves considerações em trânsito}

O objetivo basilar da proposta aqui apresentada se refere a propor a produção audiovisual de caráter experimental contextualizada no ensino de Arte, como um canal que possibilita a criação de experiências e diálogos críticos e responsáveis socialmente, em relação ao imagético midiático que protagoniza o cotidiano de todos nós. Esse olhar e posicionamento crítico, por sua vez, é expresso através da Arte com a prática experimental do vídeo.

Espera-se que este trabalho seja capaz de demonstrar a potencialidade do audiovisual experimental na cultura digital e o impacto que ela causa em nossos modos de ser e estar no mundo hoje. A partir daí, fica evidente a responsabilidade que o campo do ensino de Arte tem de abordar os fluxos audiovisuais a fim de contribuir para que os indivíduos sejam capazes de entender de fato como a imageria midiática audiovisual nos atinge.

Levando em consideração a importância da manifestação do vídeo na vida contemporânea, também é necessário que as pessoas, além de aprender a interpretar de maneira mais profunda e crítica os conteúdos que assistimos diariamente, saibam se apropriar dessa linguagem para utilizá-la em prol da expressão das próprias opiniões, afinal somos seres da comunicação. Dessa forma,

DEMARCHI, Jéssica Thaís; AZEVEDO, Cláudio Tarouco de. Vínculos entre o ensino de Arte e a linguagem audiovisual na cultura digital. Revista da FUNDARTE, Montenegro, p.63-78, ano 19, ํㅡ 38, abril/junho de 2019.

Disponível em: http://.seer.fundarte.rs.gov.br/index.php/RevistadaFundarte/index> 28 de junho de 2019. 


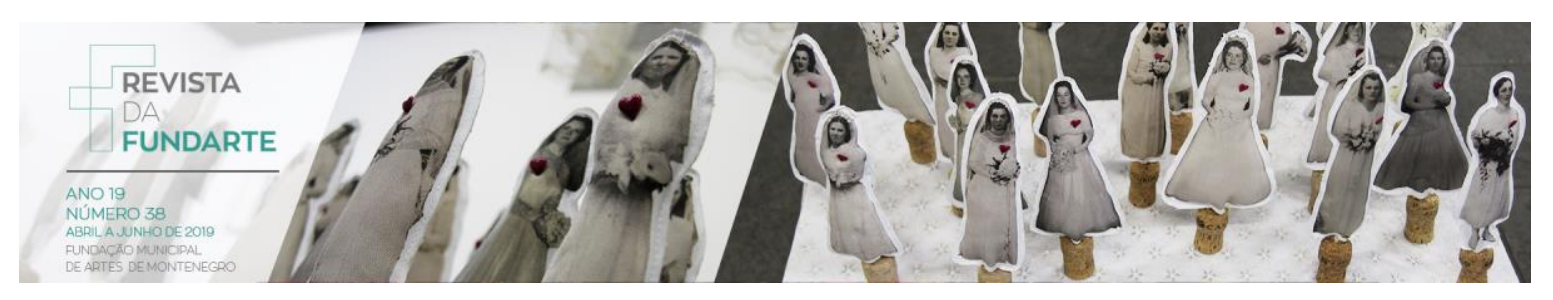

seria possível contribuir cada vez mais com o processo de descentralização do lugar de fala, democratizando assim o direto individual à expressão.

A breve explicação do mote central que dirige o funcionamento do programa de oficinas de vídeo experimental não se coloca como um modelo a ser seguido, mas apenas como uma ideia propulsora para que outros Arte-educadores possam desenvolver suas próprias ações pedagógicas com a prática artística do vídeo.

O programa em questão não é aprofundado no presente trabalho, tendo em vista que a meta principal da escrita que compõe este texto é o desejo de demonstrar o papel vital exercido pelo audiovisual na cultura digital, a fim de instigar outros educadores e educadoras a desenvolver elos de conexão entre a prática videográfica e os processos pedagógicos concernentes ao campo da Arte.

\section{Referências:}

ALMEIDA, C. Z. As relações arte/tecnologia no ensino da arte. In: PILLAR, A. D. (Org.). A educação do olhar no ensino das artes. 4. ed. Porto Alegre: Mediação, 2006. p. 71-84.

ALVES, Marcia Nogueira. Mídia e produção audiovisual: uma introdução. Curitiba: Ibpex, 2008.

DEMARCHI, Jéssica Thaís. Videografias experimentais no ensino de Arte: frames da produção de subjetividades. 193 f. 2018. Dissertação (Mestrado em Artes Visuais) Programa de Pós-Graduação em Artes Visuais, Centro de Artes, Universidade Federal de Pelotas, Pelotas, 2018.

LEMOS, André. Cibercultura: tecnologia e vida social na cultura contemporânea. 6 . ed. São Paulo:Editora Sulina, 2013.

. In: SAVAZONI, Rodrigo; COHN. Sergio (Orgs.). Cultura digital.br. São

Paulo: Azougue Editorial, 2009. p. 134-149.

MACHADO, Arlindo. Pré-cinemas e pós cinemas. 6. ed. Campinas: Papirus: 2011.

MARTINS, R; SÉRVIO, P. P. Distendendo relações entre imagens, mídia, espetáculo e educação para pensar a cultura visual. In: MARTINS, R; TOURINHO, I. (Orgs.). Culturas das imagens: desafios para a arte e para a educação. Santa Maria: Ed. Da UFSM, 2012. p. 255-282.

MELLO, Christine. Extremidades do vídeo. São Paulo: Ed. Senac São Paulo, 2008.

DEMARCHI, Jéssica Thaís; AZEVEDO, Cláudio Tarouco de. Vínculos entre o ensino de Arte e a linguagem audiovisual na cultura digital. Revista da FUNDARTE, Montenegro, p.63-78, ano 19, ํㅡ 38, abril/junho de 2019.

Disponível em: http://.seer.fundarte.rs.gov.br/index.php/RevistadaFundarte/index> 28 de junho de 2019. 